\title{
Is urinary specific gravity a useful simple marker of fluid depletion in athletes?
}

\author{
Roy J. Shephard
}

Received: 20 March 2013/ Accepted: 9 May 2013/Published online: 17 May 2013

(C) Springer-Verlag Berlin Heidelberg 2013

Hamouti et al. (2013) rightly draw attention to the need for a simple field measure of dehydration, an index that can be used by those monitoring athletes who are performing endurance exercise under hot conditions. They also note some of the limitations of drawing inferences from changes in body mass, although they do not discuss the potential complication that up to 21 of water are liberated during the metabolism of glycogen, and an equal change occurs in the opposite sense as intramuscular glycogen reserves are replenished.

The current paper of Hamouti et al. (2013) examines the ability to detect moderate dehydration by looking at the individual's urinary specific gravity. This approach was previously questioned by Popowski et al. (2001) and Oppliger et al. (2005), in part because the response lagged behind plasma osmolality and in part because changes showed a poor sensitivity and specificity relative to the plasma criterion. At the most accurate of possible cutpoints, urinary measures correctly classified hydration status in less than two-thirds of athletes, whether examining urinary specific gravity or urinary osmolality (Oppliger et al. 2005).

Nevertheless, Hamouti et al. (2013) suggested that urinary specific gravity was "as sensitive as $\mathrm{S}_{\mathrm{OSM}}$ for the detection of low levels of exercise-induced dehydration (i.e., $2 \%$ ) reported to affect athletic performance." They reached this conclusion based upon the testing of a group of 18 aerobically trained male athletes; each of their

Communicated by Klaas Westerterp/Håkan Westerblad.

R. J. Shephard $(\bowtie)$

Faculty of Kinesiology and Physical Education, University of Toronto, PO Box 521, Brackendale, BC V0N 1H0, Canada

e-mail: royjshep@shaw.ca subjects undertook repeated $20 \mathrm{~min}$ bouts of exercise at some $60 \%$ of their $\dot{V} \mathrm{O}_{2 \text { peak }}$ under hot conditions $\left(32^{\circ} \mathrm{C}\right.$, $46 \% \mathrm{RH})$ until their body mass had decreased by $3 \%$. Already, at a $2 \%$ decrease in body mass, the average urinary specific gravity for the group (1.023) was significantly above its baseline value of $1.018(p<0.05)$.

Unfortunately, this observation does not prove the value of urinary specific gravity measurements when advising the individual competitor. Inspection of the authors' Fig. 1 shows a substantial variation in both baseline and dehydration data; assuming a normal data distribution, the respective $95 \%$ confidence limits would approximate $1.010-1.026$ and 1.017-1.029. Given this degree of overlap, it would seem very difficult to draw conclusions about the hydration status of an individual athlete. Possibly, some of the inter-individual variability could be eliminated and a clearer distinction between euhydration and dehydration would become possible if the authors were to calculate the change of urinary specific gravity within each subject. I would encourage them to pursue such an analysis.

\section{References}

Hamouti N, Del Coso J, Mora-Rodriguez R (2013) Comparison between blood and urinary fluid balance indices during dehydrating exercise and the subsequent hypohydration when fluid is not restored. Eur J Appl Physiol 113:611-620

Oppliger RA, Magnes SA, Popowski LA (2005) Accuracy of urinary specific gravity and osmolality as indicators of hydration status. Int J Sport Nutr Exerc Metab 15:236-251

Popowski LA, Oppliger RA, Patrick Lambert G et al (2001) Blood and urinary measures of hydration status during progressive acute dehydration. Med Sci Sports Exerc 33:747-753 